\title{
Processamento tecidual para análise imunoistoquímica de receptores hormonais em carcinoma mamário: dois momentos em um laboratório de anatomia patológica; correlação dos resultados com método bioquímico
}

Tissue processing for hormone receptor immunohistochemistry in breast cancer: two moments in a pathology laboratory; correlation of results with a biochemical assay

\author{
Victor Arias ${ }^{1}$ \\ Pedro Luiz Mazza² \\ Marcelo Antonio Aranha Funke
}

\section{unitermos}

Câncer da mama/ patologia

Imunoistoquímica/métodos

Marcadores bioquímicos

de tumor/análise

Receptores hormonais

nucleares

\section{resumo}

A reação imunoistoquímica é altamente dependente da fixação e da preparação histológica do tecido.

Nós comparamos os resultados da pesquisa de receptores de estrógeno e de progesterona no câncer mamário utilizando um método bioquímico e um método imunoistoquímico em relação ao tipo de processamento histológico, no forno de microondas ou na estufa. O grupo de casos cujos tecidos foram processados no forno de microondas não apresentou correlação entre os dois métodos $(p=0,098$ para o receptor de estrógeno; $p=0,5$ para o receptor de progesterona). Houve boa correlação entre os métodos nos tecidos processados na estufa ( $p=0,0447$ e $Q=0,76$ para o receptor de estrógeno; $p=0,0472$ e $\mathrm{Q}=0,764$ para o receptor de progesterona). Concluímos que a pesquisa de receptores hormonais por reação imunoistoquímica no câncer mamário é uma realidade, apresentando bons resultados desde que sejam tomados cuidados na fixação e no processamento e que sempre sejam utilizados controles externos adequados à realidade de cada laboratório.

\section{abstract}

Immunohistochemistry is highly dependent on tissue fixation and histologic processing. We compared the results of estrogen and progesterone receptor quantitation determined by using both a biochemical method and an immunohistochemical method related with tissue preparation, either in the microwave oven or in the stove. The group of cases whose tissues were processed in the microwave oven did not present statistical correlation between the methods ( $p=0,098$ to estrogen receptor; $p=0,5$ to progesterone receptor). There was good correlation between the methods in tissues which were processed in the stove ( $p=0,0447$ and $Q=0,76$ for estrogen receptor; $p=0,0472$ and $Q=0,764$ for progesterone receptor). We conclude that immunohistochemistry for hormone receptors in breast cancer is a reality. It is feasible since some cautions are taken in the fixation and processing. External controls appropriated to the reality of a given laboratory should always be used. key words

Breast cancer/ pathology

Immunohistochemistry/methods

Cytosol assay

Hormone receptors
1. Médico do Instituto de Patologia Cardoso de Almeida e do Instituto Adolfo Lutz; mestre em Patologia Humana pela Faculdade de Medicina de Ribeirão Preto/USP; doutor em Ciências, área de oncologia, pela Fundação Antônio Prudente.

2. Médico do Serviço de Mastologia do Hospital Evaldo Foz. Trabalho realizado no Laboratório de Patologia Cardoso de Almeida

e no Laboratório Criesp. apresentar melhor resposta à terapia anti-hormonal e maior sobrevida, tanto livre de doença, quanto global $(6,11)$.

O método de detecção de receptores hormonais no tecido neoplásico deve ser, então, seguro, altamente reprodutível e clinicamente relevante (8). Métodos bioquíção de casos de câncer mamário está relacionada tanto ao valor preditivo para resposta a terapia endócrina quanto ao seu valor prognóstico. Pacientes com tumores que expressam receptores hormonais tendem a 
micos de detecção dos receptores hormonais carregam a vantagem de trabalhar com resultados quantitativos, mas têm como desvantagem dependerem de tecido fresco e não se apoiarem na morfologia da lesão $(5,8)$, uma vez que a amostra representada pelo homogeneizado tecidual pode conter, além de células neoplásicas, células estromais e células do epitélio não-neoplásico. Métodos de detecção in situ, como a imunoistoquímica, podem ser realizados em material de arquivo, fixado em formol e incluído em parafina, utilizando-se a morfologia tecidual para detectar células neoplásicas positivas, mas os resultados são qualitativos e não indicam se a proteína marcada é funcional ou não $(5,8)$.

O método imunoistoquímico, principalmente após o desenvolvimento de anticorpos capazes de reconhecer epitopos que não se degradam durante o processamento histológico, tem, na prática, gradativamente, substituído o método bioquímico, antes tido como o padrão-ouro, para a avaliação dos receptores hormonais $(6,8,9)$. Os resultados do método imunoistoquímico dependem de variáveis como o tipo de fixador utilizado, o tempo de fixação do material, a temperatura de processamento e o método de recuperação antigênica utilizado $(2,7)$. À exceção do último, os outros nem sempre podem ser padronizados, pois são procedimentos que ocorrem à distância do laboratório de patologia ou, então, variam de laboratório para laboratório.

O presente trabalho tem dois objetivos. O primeiro, comparar os resultados obtidos na pesquisa de receptores de estrógeno e de progesterona no câncer mamário utilizando um método bioquímico e um método imunoistoquímico. O segundo, utilizando o método bioquímico como padrão-ouro, verificando a confiabilidade do método imunoistoquímico em relação ao tipo de processamento histológico. Para tal, utilizamos material de arquivo coletado em duas épocas diferentes no que diz respeito a tais variáveis em nosso laboratório.

\section{Material e métodos}

Foram estudados 44 carcinomas mamários de muIheres operadas no Setor de Mastologia do Hospital Evaldo Foz (São Paulo) entre 1993 e 1999. Estes foram categorizados segundo a data da coleta do material em grupo A, coleta no período de 1993 a 1995 (18 casos), e grupo B, coleta nos anos de 1996 a 1999 (26 casos). Durante o ato cirúrgico era realizado exame peroperatório pelo método de congelação, no qual, além do diagnós- tico, o patologista escolhia um fragmento constituído exclusivamente por tecido neoplásico para pesquisa de receptores de estrógeno e progesterona por método bioquímico. Este fragmento de aproximadamente $0,5 \mathrm{~cm}^{3}$ era, então, congelado em nitrogênio líquido para preparação do citossol. O restante do material e a peça cirúrgica correspondente eram fixados em formol a $10 \%$ por um período que variava de 12 a 36 horas e seguiam para processamento histológico. O material do grupo A foi processado de acordo com as recomendações de Boon e Kok (3), utilizando-se um forno de microondas convencional (marca Sharp, modelo MW620A), com potência de $700 \mathrm{~W}$ e tempo e temperatura ajustáveis (Tabela 1 ). $O$ material do grupo $B$ foi processado a quente em estufa convencional (Tabela 2).

O fragmento congelado em nitrogênio líquido era enviado à Central de Imunoensaio de São Paulo (Criesp), onde o tecido era pulverizado para a obtenção do citossol. Então, a pesquisa de receptores de estrógeno e progesterona era realizada pelo método do carvão-dextrano, como previamente descrito (4). Níveis maiores ou iguais a 10 fentomoles/mg foram considerados positividade para receptor de estrógeno. Para serem considerados positivos para receptor de progesterona, os níveis deveriam ser de 20 fentomoles/mg ou maiores.

Os blocos de parafina arquivados no Laboratório de Patologia Cardoso de Almeida (São Paulo) foram recuperados para a reação imunoistoquímica. Tomamos o cuidado de escolher amostras que não foram submetidas ao exame de congelação peroperatório. Os cortes histológicos de tecido mamário foram montados em lâminas previamente sinalizadas (3-aminopropiltrietoxisilano, marca Sigma). Após desparafinização e reidratação, foram imunocorados utilizando-se o método do complexo streptavidina-biotina-peroxidase (kit LSAB+, Dako).

Método de processamento tecidual em forno de microondas utilizado no Laboratório de Patologia Cardoso de Tabela 1 Almeida no período de 1993 a 1995
Banho

Formol a $10 \%$

Álcool absoluto

Álcool absoluto

Xilol

Parafina
Tempo ( $\mathrm{min})$

10

10

15

5

20
Temperatura $\left({ }^{\circ} \mathrm{C}\right)$ 55

55

62

77

65 
Método de processamento tecidual em estufa convencional utilizado no Laboratório de Patologia Cardoso de Tabela 2 Almeida no período de 1996 a 1999

\begin{tabular}{lcc}
\hline Banho & Tempo $(\mathrm{min})$ & Temperatura $\left({ }^{\circ} \mathrm{C}\right)$ \\
Álcool absoluto & 20 & 70 \\
Álcool absoluto & 20 & 70 \\
Álcool absoluto & 20 & 70 \\
Álcool absoluto & 20 & 70 \\
Xilol & 10 & 70 \\
Xilol & 10 & 70 \\
Parafina & 30 & 62 \\
Parafina & 30 & 62 \\
\hline
\end{tabular}

O bloqueio da peroxidase endógena foi alcançado lavando-se as lâminas com água oxigenada a 3\%, e a recuperação antigênica, por calor úmido em panela a vapor (steamer) por 60 minutos em tampão citrato $10 \mathrm{mM}$, $\mathrm{pH}$ 6. Os anticorpos primários utilizados foram o anti-receptor de estrógeno (clone 1D5, monoclonal, Dako) diluído a 1/100 e o anti-receptor de progesterona (clone 1A6, monoclonal, Dako) diluído a $1 / 200$. Para controle positivo utilizamos amostras de carcinoma endometrial sabidamente positivas para os marcadores pesquisados e processadas de maneira semelhante às amostras de carcinoma mamário em teste. Para controle negativo, substituímos o anticorpo primário por solução salina tamponada (PBS). À avaliação dos resultados, aceitamos como positivas as reações nos tecidos em que havia pelo menos $5 \%$ dos núcleos marcados (6).

Para estudar os resultados estatisticamente, isto é, para verificar se há concordância entre os métodos utilizados, no mesmo indivíduo, em cada um dos grupos, utilizamos o teste exato de Fisher. Para verificarmos a magnitude e o sinal da associação utilizamos o coeficiente de associação de Yule (Q).

\section{Resultados}

A reação imunoistoquímica, quando positiva, tanto para o receptor de estrógeno quanto para o receptor de progesterona, corou os núcleos celulares. Geralmente havia um número bem maior que os $5 \%$ de núcleos positivos requeridos para diagnóstico de positividade. No grupo A (casos coletados no período de 1993 a 1995), notamos que os cortes tendiam a descolar das lâminas e as amostras apresentavam artefatos de corte como o aspecto em veneziana, causado por trepidação do bloco de parafina no suporte do micrótomo. Provavelmente este artefato foi causado pela consistência endurecida do tecido emblocado. Houve variações na intensidade da reação dentro de um mesmo corte, produto de fixação irregular do material. Quando comparamos as várias reações, pudemos verificar também alta variabilidade na intensidade de caso para caso. Ao compararmos as reações para os diferentes marcadores, percebemos que os resultados para o receptor de estrógeno foram mais consistentes, isto é, mais homogêneos de caso para caso (Figura 1).

No grupo B (casos coletados entre 1996 e 1999), verificamos menor tendência de descolamento dos cortes histológicos e os artefatos praticamente não existiram, obtendo-se, assim, morfologia perfeita, mesmo após a prolongada exposição ao calor úmido na câmara a vapor. Também verificamos que as reações, além de mais homogêneas, deram resultados mais consistentes com intensidade maior e mais homogênea pelo corte histológico. Quando comparamos com os resultados das reações para receptor de estrógeno com as realizadas para pesquisa de receptor de progesterona, verificamos que as últimas apresentavam intensidade menor, assim como um número menor de núcleos marcados (Figura 2).

A distribuição dos resultados referentes às reações imunoistoquímicas e às pesquisas dos receptores hormonais pelo método do carvão-dextrano estão expostas nas Tabelas 3 e 4. Brevemente, no grupo A, para o receptor de estrógeno, houve coincidência de resultados positivos em dois casos, de resultados negativos em 12 casos e disparidade de resultados em quatro casos. Tais resultados mostraram independência estatística entre os dois métodos $(p=0,098)$. No grupo $B$, houve coincidência de

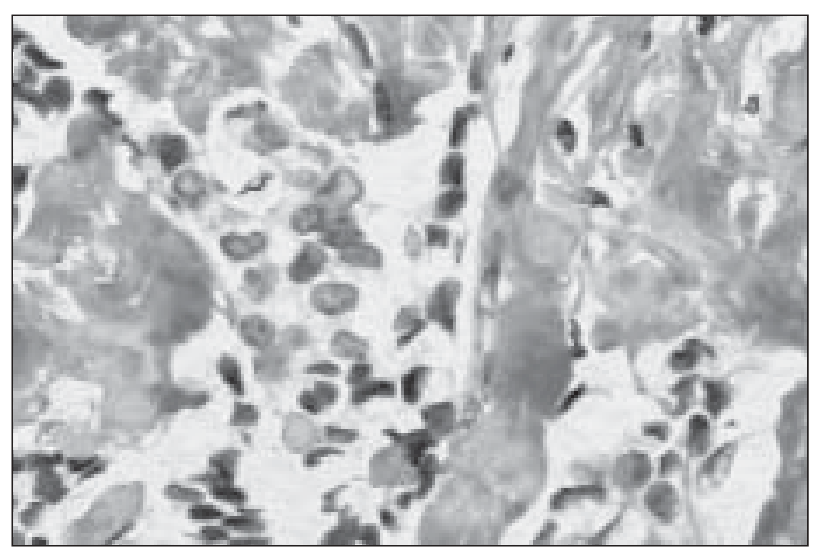

Figura 1 - Reação imunoistoquímica para pesquisa de receptor de estrógeno (anticorpo 1D5) em material processado histologicamente em forno microondas 


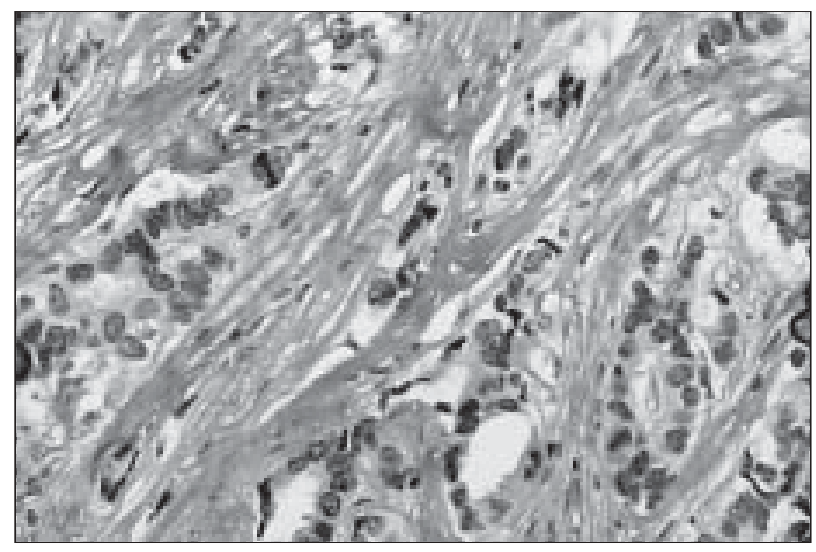

Figura 2 - Reação imunoistoquímica para pesquisa de receptor de estrógeno (anticorpo 1D5) em material processado histologicamente em estufa

resultados positivos em 11 casos e de resultados negativos em oito casos e disparidade de resultados em sete casos. Tais resultados mostraram associação estatística entre os dois métodos ( $p=0,0447)$. No grupo $\mathrm{A}$, para o receptor de progesterona, houve coincidência de resultados positivos em dois casos e de resultados negativos em oito casos e disparidade de resultados em oito casos. Tais resultados mostraram independência estatística entre os dois métodos $(p=0,5)$. No grupo $B$, houve coincidência de resultados positivos em nove casos e de resultados negativos em dez casos e disparidade de resultados em sete casos. Tais resultados mostraram associação estatística entre os dois métodos ( $p=0,0472)$. O índice de associação de Yule demonstrou boa associação estatística entre os dois métodos no grupo $B$, tanto para o receptor de estrógeno $(\mathrm{Q}=+0,76)$ quanto para o receptor de progesterona $(\mathrm{Q}=+0,764)$.

\section{Discussão}

A pesquisa de receptores de estrógeno e progesterona passou a ter papel importante no acompanhamento de pacientes com câncer de mama devido ao seu valor preditivo à resposta terapêutica anti-hormonal. Pacientes com tumores que expressam ambos os marcadores têm um índice de resposta ao tratamento com tamoxifeno de $78 \%$, enquanto que aquelas com expressão negativa destes receptores hormonais apresentam um índice de resposta terapêutica de $10 \%$ (1).

Esses receptores hormonais podem ser pesquisados tanto por métodos bioquímicos quanto por métodos

Frequiência dos resultados obtidos nos grupos A e B para pesquisa de receptor de estrógeno (grupo A, processamento histológico em forno de microondas, período de 1993 a 1995; grupo B, processamento histológico a quente em estufa convencional, Tabela 3 período de 1996 a 1999)

\begin{tabular}{lcccccc}
\hline & & & Imunoistoquímica & \\
Carvão-dextrano & & Grupo A & & & Grupo B & Total \\
& Positivo & Negativo & Positivo & Negativo & 17 \\
Positivo & 2 & 0 & 11 & 4 & 27 \\
Negativo & 4 & 12 & 3 & 8 & $\mathbf{1 2}$ \\
Total & $\mathbf{6}$ & $\mathbf{1 2}$ & $\mathbf{1 4}$ & $\mathbf{4 4}$ \\
\hline
\end{tabular}
Tabela 4 período de 1996 a 1999)

Freqüência dos resultados obtidos nos grupos A e B para pesquisa de receptor de progesterona (grupo A, processamento histológico em forno de microondas, período de 1993 a 1995; grupo B, processamento histológico a quente em estufa convencional,

\section{Imunoistoquímica}

\begin{tabular}{lcc} 
Carvão-dextrano & \multicolumn{1}{c}{ Grupo A } \\
\cline { 2 - 2 } & Positivo \\
Positivo & 2 \\
Negativo & 7 \\
Total & 9
\end{tabular}

Negativo

1

8

9

$$
\text { Grupo B }
$$

Positivo Negativo

12

14 
morfológicos como a imunoistoquímica. Após o desenvolvimento de anticorpos que reconhecem epitopos dos receptores hormonais com segurança, em material fixado em formol a $10 \%$ e fixados em parafina, houve uma tendência a substituir o método bioquímico pelo imunoistoquímico. $\mathrm{O}$ custo e a complexidade do método bioquímico são fatores que contribuíram para esta decisão. Ainda, deve-se levar em consideração que o método bioquímico necessita de grandes amostras de tecido, havendo restrições em tumores de diâmetro menor que $1 \mathrm{~cm}$.

As desvantagens do método imunoistoquímico residem especialmente na variabilidade de resultados tanto interobservador quanto interlaboratorial. O método ressente-se da falta de padronização tanto da reação em si, na qual são utilizados, para o mesmo fim, clones diferentes de anticorpos, diferentes métodos de fixação, de recuperação antigênica e métodos de amplificação da reação, quanto da padronização de expressão dos resultados, havendo diferentes sistemas, como a obtenção de escores segundo o número de núcleos marcados e sua intensidade, ou então simplesmente relatando uma proporção de núcleos positivos tanto por um sistema de cruzes quanto por um de porcentagem estimada, ou contagem real por unidade de área. Neste trabalho, escolhemos quantificar por estimação do número de núcleos marcados, utilizando um cut-off de $5 \%$, já que nos interessava apenas categorizar qualitativamente os resultados em positivos e negativos.

O foco deste trabalho, além da comparação entre os métodos bioquímico e imunoistoquímico, está na avaliação do processamento histológico. Tentamos, na medida do possível, eliminar as demais variáveis. A fixação permaneceu a mesma, utilizando-se formol a $10 \%$ produzido da mesma forma nos seis anos em que o material foi coletado. $O$ tempo de fixação variou de 12 a 36 horas. Todas as reações imunoistoquímicas foram realizadas em um só tempo, ficando todas as lâminas expostas às mesmas condições de trabalho. Todas as reações foram avaliadas de uma vez para evitarmos vieses de interpretação.

Assim, comparamos dois tipos de processamento histológico a quente, isto é, que utiliza banhos com temperatura aumentada com a intenção de se diminuir o tempo de processamento. Boon e Kok (3) estabeleceram as bases do processamento em forno de microondas. A maioria dos materiais assim processados, quando corados pela hematoxilina e pela eosina, não apresentou diferenças morfológicas importantes. A nossa experiência, porém, revelou que alguns tecidos ricos em colágeno, quan- do submetidos a alterações bruscas de temperatura dos banhos durante o processamento, podem sofrer desidratação além da desejada e tornar-se mais duros e difíceis de serem cortados à microtomia. Este é o caso de tumores mamários que na maioria das vezes apresentam algum grau de reação desmoplásica. É importante salientar que, dadas as características do forno de microondas por nós utilizado, tínhamos a possibilidade de controlar tanto a temperatura quanto o tempo de cada banho e, assim, garantir que nenhum material foi submetido a uma temperatura acima da qual há degradação dos antígenos. Mesmo assim, verificamos que os resultados da reação imunoistoquímica do material assim processado não foram tão satisfatórios, com heterogeneidade e baixa intensidade de imunocoloração. Estes resultados causaram, até certo ponto, alguma surpresa, desde que, historicamente, a idéia de se submeter lâminas ao calor úmido em forno de microondas para recuperação antigênica em tampão tiocianato de chumbo nasceu da observação de que tecidos submetidos ao processamento histológico no forno de microondas coravam-se melhor à imunoistoquímica do que aqueles que sofriam processamento convencional (10).

Quando estudamos os resultados da pesquisa de receptores hormonais pelo método imunoistoquímico, utilizando os resultados do método bioquímico como padrão-ouro, verificamos que não há diferença estatística entre os resultados desses métodos quando utilizamos o processamento histológico a quente em estufa convencional $(p=0,447 ; \mathrm{Q}=+0,76$ para o receptor de estrógeno $\mathrm{e}$ $p=0,0472 ; \mathrm{Q}=+0,764$ para o receptor de progesterona). Mesmo assim, notamos resultados discrepantes, positivos no método bioquímico e negativos no método imunoistoquímico e vice-versa. Gordts et al. (5) encontraram diferenças de até $23 \%$ entre os dois métodos. Kell et al. (7) tentaram especular sobre as possíveis fontes de diferenças, embora tenha havido casos sem que se encontrassem explicações plausíveis. No nosso caso não podemos considerar falso positivo no método bioquímico por amostragem errônea, já que o exame peroperatório por congelação evitou o viés de se incluir tecido não-neoplásico para exame, fato que se confirmou após se ter incluído o tecido controle em parafina.

Finalmente, devemos considerar com o exposto que a pesquisa de receptores hormonais por reação imunoistoquímica no câncer mamário é uma realidade e apresenta bons resultados. É importante chamar a atenção, no entanto, para o fato de que no primeiro período 
estudado houve excessivo número de resultados negativos para o método bioquímico. É possível que isso tenha se devido a resultados falsos negativos, provavelmente decorrentes do pequeno tamanho da amostra enviada para o laboratório. Chamamos a atenção para o fato de que a padronização do método deve ser iniciada logo à fixação do material no centro cirúrgico com treinamento adequado do pessoal de enfermagem, passando pelo processamento histológico e finalizando com o exame criterioso dos resultados das reações, utilizando-se para tal tanto controles externos confiáveis como o controle interno positivo. A escolha dos controles externos deve residir não somente na positividade da reação, mas também no tipo de fixação e no processamento do material, que devem ser semelhantes ao do tecido em estudo, desta forma protegendo o patologista de possíveis erros de avaliação secundários a má fixação e artefatos de processamento do material.

\section{Referências}

1. [A nonymous]. Steroid receptors in breast cancer: an N IH C onsensus D evelo pment Conference, Bethesda, Maryland, June 27-29, 1979. Cancer, 46(12 suppl.): 2759-963, 1980.

2. A rias, V.E.A. et al. Imunoistoquímica aplicada ao diagnóstico: 1. Encaminhamento de peças do centro cirúrgico ao laboratório de patologia. Medicina, 28: 39-43, 1995.

3. Boon, M A. \& Kok, L.P. M icrowave cookbook of pathology: The art of microscopic visualization. Leiden: Coulomb Press Leyden, 1987.

4. Brentani, M.M.;N agai, M.A.\& G oes, J.C .S. Steroid receptors in a group of Brazilian breast cancer patients.J. Surg. Oncol., 18(4): 431-9, 1981.

5. Gordts, S.L. et al. The immunocytochemical versus cytosomeasurement of the oestrogen receptor in invasive breast cancer tissue. Eur. J. Cancer, 36: S20-S21, 2000.

6. Harvey,J.M .et al.Estrogen receptor status by immunohistochemistry is superior to the ligand-binding assay for predicting response to adjuvant endocrine therapy in breast cancer.J. Clin. Oncol., 1474-81, 1999.
7. Kell et al. Immunohistochemical analysis of breast carcinoma estrogen and progesterone receptors in paraffinembedded tissue: correlation of clones ERID 5 and $1 A 6$ with a cytosol-based hormone receptor assay. Appl. Immunohistochem., 1:275-81, 1993.

8. Leake, R. detection of the oestrogen receptor (ER): immunohistochemical versus cytosol measurements. Eur. J. Cancer, 36:S18-S19, 2000.

9. Lohmann, $C$.et al. Progesterone receptor immunohistochemical quantitation compared with cytolosic assay:correlation with prognosis in breast cancer. AlM M , 9: 49-53, 2001.

10. Shi, S.R.; Key, M.E. \& Kalra, K. L. Antigen retrieval in formalinfixed, paraffin-embedded tissues: an enhancement method for immunohistochemical staining based on microwave oven heating of tissue sections. J. H istochem. Cytochem., 39(6): 741-8, 1991.

11.W itliff,J. L. Steroid-hormone receptors in breast cancer. Cancer 53(3 suppl.): 630-43, 1984.
Endereço para correspondência

Victor Arias

Rua Conselheiro Brotero $1.505 / 8^{\circ}$ andar

Santa Cecília

CEP 01232-011 - São Paulo-SP

Tel.: (11) 3826-3400

e-mail: varias@cardosodealmeida.com.br 